\title{
Assessment of mortality post-ICU associated to the intensive care unit length of stay
}

\author{
F Gómez Triana*, P Carcelén Rodríguez, ZE Aray Delpino, D Monge Donaire, TL Álvarez Pérez, FC Tarancón Maján, \\ SM Cortés Díaz, A Marcos Gutiérrez, AC Caballero Zirena
}

From ESICM LIVES 2015

Berlin, Germany. 3-7 October 2015

\section{Introduction}

Patients admitted to the ICU may require longer stays, which in turn can influence the evolution of their disease. This may be a determining factor of their overall prognosis and result in modifications to previously determined morbidity and mortality.

\section{Objective}

To establish prolonged effects of mortality following patients with prolonged stays in the ICU once they are transferred to the general ward, and identify possible reasons associated with this mortality.

\section{Methods}

This is a retrospective study of ICU patients during 2013 at the Virgen de la Concha Hospital (Zamora, Spain). 445 patients admitted during the study period were identified as having a prolonged ICU stay defined as equal to, or greater than 10 days. Patients were evaluated following transfer from the ICU to the general ward until death or discharge. Epidemiological data, diagnosis at admission and estimation of risk of death, were assessed by APACHE II scores.

\section{Results}

The overall ICU mortality rate was $12.58 \%$ (IC 95\%: 9,39-15,7), that is 56 of the 445 patients that were included during the study period. 53 patients had a prolonged stay $(11,9 \%) ; 10$ of which expired during their stay in the ICU (18\%). The remaining 43 were discharged to the general ward. Of these 43 ward transfers, 11 (25\%) expired during their stay on the ward (IC 95\%: 11,3-39,7) and the remaining 32 were discharged to home. The expected deaths were $28 \%$ and the observed deaths $25 \%$ (Standardized mortality ratio of $0.89 ; 95 \% \mathrm{CI}, 0.39$ to 1,38$)$. The average stay in the general ward post-ICU was $17.74 \pm 23.98$ days.

\section{Conclusions}

Prolonged stay in the ICU is a determining factor that influences patients mortality following their transfer to the general ward. The high mortality can be predicted on the APACHE II system applied to our patient population. As a result, the APACHE II system may assist the clinician in determining which patients are at increased risk of mortality, and thus devise ways to circumvent such events in the patients with prolonged ICU stays.

Published: 1 October 2015

\section{References}

1. Martin CM, Hill AD, Burns K, Chen LM: Characteristics and outcomes for critically ill patients with prolonged intensive care unit stays. Crit Care Med 2005, 33:1922-1936.

2. Higgins TL, McGee WT, Steingrub JS, Rapoport J, et al: Early indicators of prolonged intensive care unit stay: impact of illness severity, physician staffing, and pre-intensive care unit length of stay. Crit Care Med 2003, 31:45-51.

3. Laupland KB, Kirkpatrick AW, Kortbeek JB, Zuege DJ: Long-term mortality outcome associated with prolonged admission to the ICU. Chest 2006, 129:954.

4. Abizanda Campos R, Altaba Tena S, Belenguer Muncharaz A, et al: Study of post-ICU mortality during 4 years (2006-2009). Analysis of the factors related to death in the ward after discharge from the ICU. Med Intensiva 2011, 35(3):150-156.

doi:10.1186/2197-425X-3-S1-A968

Cite this article as: Gómez Triana et al:: Assessment of mortality postICU associated to the intensive care unit length of stay. Intensive Care Medicine Experimental 2015 3(Suppl 1):A968. 